\title{
Appropriateness of Lyme Disease Serologic Testing
}

\author{
Alan H. Ramsey, MD, MPH\&TM"1,2 \\ Edward A. Belongia, $M D^{3}$ \\ Po-Huang Chyou, $\mathrm{PbD}^{3}$ \\ Jeffrey P. Davis, $M D^{1}$
}

'Bureau of Communicable Diseases, Wisconsin Division of Public Health, Madison, Wis

${ }^{2}$ Epidemic Intelligence Service, Division of Applied Public Health Training, Epidemiology Program Office, Centers for Disease Control and Prevention, Atlanta, Ga

${ }^{3}$ Marshfield Clinic Research Foundation, Marshfield Clinic, Marshfield, Wis

Conflicts of interest: none reported

\section{CORRESPONDING AUTHOR}

Edward A. Belongia, MD

Epidemiology Research Center

Marshfield Clinic Research Foundation

1000 N. Oak Ave

Marshfield, WI 54449

belongia.edward@mmrf.mfldclin.edu

\begin{abstract}
BACKGROUND Although rapid diagnosis of Lyme disease is essential for effective treatment, there is concern about inappropriate testing. We conducted a prospective, cross-sectional survey of clinicians to assess the use and appropriateness of Lyme disease serologic tests (LDSTs).
\end{abstract}

METHODS LDSTs performed at 2 large Wisconsin reference laboratories were systematically sampled for 12 consecutive months. A standardized questionnaire was used to gather data about the submitting clinician and the patient tested. Tests were categorized as appropriate, inappropriate, or discretionary, and associations were assessed using logistic regression analysis. A test was defined as inappropriate if the patient was asymptomatic, had erythema migrans, or was treated empirically, or if the test was ordered as a test of cure.

RESULTS We surveyed 303 clinicians regarding 356 LDSTs: 72 tests (20\%) were appropriate, 95 (27\%) were inappropriate, and 189 (53\%) were discretionary. Tests were more likely to be inappropriate if they were ordered by an emergency or urgent care physician compared with other specialists (adjusted odds ratio [AOR] 5.2, 95\% confidence interval [Cl], 1.3-20.6), or if preceded by a known tick bite (AOR 6.8, 95\% Cl, 2.6-17.6). The patient rather than the clinician requested $26 \%$ of tests, which were more likely to be inappropriate than clinicianrequested tests (crude odds ratio [COR] 5.8,95\% Cl, 2.5-13.6). Tests were more likely to be patient-requested if they were ordered by an internist (AOR 2.6, 95\% $\mathrm{Cl}, 1.4-4.8$ ) or if the patient was $\geq 40$ years old (AOR $2.2,95 \% \mathrm{Cl}, 1.3-3.9$ ).

CONCLUSIONS Many LDSTs are ordered inappropriately, often influenced by patient demand. Education of clinicians and patients about testing indications and contraindications is needed to reduce the number of inappropriate LDSTs.

Ann Fam Med 2004;2:341-344. DOI: 10.1370/afm.117.

\section{INTRODUCTION}

L yme disease is a multisystem tick-borne infection caused by the spirochete Borrelia burgdorferi. ${ }^{1,2}$ Erythema migrans, the characteristic Lexpanding rash of early localized Lyme disease, is present in at least $80 \%$ of cases, and joint, neurologic, cardiac and other manifestations may develop. ${ }^{3}$ In the absence of erythema migrans, antibodies to $B$ burgdorferi are generally required to diagnose Lyme disease. ${ }^{3,4}$ Approximately 2.8 million Lyme disease serologic tests (LDSTs) are performed each year in the United States according to a 1995 estimate. ${ }^{4}$ At $\$ 40$ per test, a conservative figure, the annual direct medical expenditure for LDSTs would exceed $\$ 100$ million.

There is persisting concern that LDSTs are used inappropriately by clinicians. ${ }^{5-7}$ Early serologic testing based only on tick bite or potential exposure to ticks has low sensitivity and specificity and is not recommended. ${ }^{8}$ For patients who live in areas where Lyme disease is endemic, and who have erythema migrans, serologic testing is not routinely recommended. The likelihood that these patients have Lyme disease exceeds the positive 
predictive value of serologic testing, and the negative predictive value of serologic testing of these patients is exceedingly low. ${ }^{9,10}$

To assess factors contributing to appropriate and inappropriate use of LDSTs, we conducted a prospective, cross-sectional survey of clinicians ordering LDSTs.

\section{METHODS}

We surveyed clinicians who submitted specimens for Lyme disease serologic testing (enzyme immunoassay or immunofluorescence assay) to 2 large clinical reference laboratories in Wisconsin. Up to 30 consecutive tests per month were selected from each laboratory during October 1999 through September 2000. No more than 2 tests per clinician were sampled during the study.

Consenting clinicians or other providers with access to the medical record completed a standardized survey questionnaire by telephone. Data gathered pertained to clinician characteristics and clinical circumstances related to each test.

Tests were classified as appropriate, inappropriate, or discretionary (indeterminate appropriateness) using clinical criteria based on published recommendations., ${ }^{3,4,8-10}$ A test was defined as appropriate if the patient had any objective findings consistent with disseminated Lyme disease, including joint, neurologic, or cardiac symptoms, such as arthritis, lymphocytic meningitis, cranial neuritis, or atrioventricular conduction defects. A test was defined as inappropriate if the patient was asymptomatic, had clinician-diagnosed erythema migrans, or was treated empirically with antibiotics, or the test was ordered as a test of cure (Table 1). Because evidencebased practice guidelines do not address Lyme disease testing for other clinical symptoms (eg, arthralgias, myalgias, malaise, or fatigue), the test was defined as discretionary if it met none of these criteria.

Associations were assessed using univariate unconditional logistic regression analysis with calculation of odds ratios (OR) and 95\% confidence intervals (CI). Variables associated with inappropriate tests $(P \leq .10)$ were entered into a multivariate unconditional logistic

\section{Table 1. Appropriate and Inappropriate Indications For Lyme Disease Serologic Testing in Lyme-Endemic Regions

\begin{tabular}{ll}
\hline Appropriate & Inappropriate \\
\hline Patient with oligoarticular arthritis & Patient is asymptomatic \\
Patient with cranial neuritis & Patient with clinician-diagnosed erythema migrans \\
Patient with lymphocytic meningitis & Patient treated empirically with antibiotics \\
Patient with atrioventricular block & Serologic test ordered as a test of cure \\
Patient with carditis & \\
\hline
\end{tabular}

Note: If patient does not meet any of the above criteria for appropriateness, the decision to order a Lyme disease serologic test is left to the discretion of the clinician. regression model using forward stepwise selection, followed by backward elimination. Discretionary tests were excluded from this analysis. All reported $P$ values are 2 -sided and $P \leq .05$ was considered statistically significant. Statistical analyses were done with SAS version 6.12 (SAS Institute, Cary, NC).

\section{RESULTS}

We sampled 408 LDST requests, and 356 (87\%) survey questionnaires were completed; 250 clinicians completed 1 questionnaire, and 53 completed 2 questionnaires. Forty clinicians refused to participate, and 12 could not be reached.

Of the 356 LDST requests, $20 \%$ were classified as appropriate, $27 \%$ inappropriate, and $53 \%$ discretionary. Reasons for classifying tests as inappropriate were not mutually exclusive and included absence of symptoms (55\%), empiric antibiotic treatment $(27 \%)$, test of cure $(27 \%)$, and diagnosis of erythema migrans (24\%). Stratified by specialty, family physicians, internists, and emergency and urgent care physicians ordered $70 \%$ of all tests and $75 \%$ of inappropriate tests (Table 2 ).

Patients initiated $27 \%$ of LDST requests (Table 2 ). Factors associated with patient-initiated testing included submission by a general internist (adjusted odds ratio $[\mathrm{AOR}] 2.6,95 \% \mathrm{CI}, 1.4-4.8)$ and patient age of 40 years and older (AOR 2.2, 95\% CI, 1.3-3.9).

Patient-initiated tests were more likely to be inappropriate than tests initiated by clinicians (Table 3). Other characteristics significantly associated with inappropriate tests by univariate analysis included known or suspected tick bite within 30 days of illness onset, test ordered by an emergency or urgent care physician, and test done during the summer. Patient referral from another clinician and patient hospitalization were associated with a reduced likelihood of inappropriate testing.

Two factors were independently associated with inappropriate testing in the multivariate analysis: known or suspected tick bite within 30 days of illness onset, and test ordered by an emergency or urgent care clinician (Table 3 ). The reasons for inappropriate testing by emergency or urgent care physicians were not significantly different from those for other physicians.

\section{DISCUSSION}

Our study results show that only 20\% of LDST requests were appropriate, and at least $27 \%$ were inappropriate. Inappropriate Lyme disease serologic testing represents an inefficient use of health care resources and may con- 
Table 2. The Number of Appropriate, Inappropriate and Discretionary Lyme Disease Serologic Test Requests by Clinical Specialty and by Source of Test Initiation

\begin{tabular}{lcccc}
\hline Characteristic & No. & $\begin{array}{c}\text { Appropriate } \\
\text { No. (\%) }\end{array}$ & $\begin{array}{c}\text { Inappropriate } \\
\text { No. (\%) }\end{array}$ & $\begin{array}{c}\text { Discretionary } \\
\text { No. (\%) }\end{array}$ \\
\hline Clinical specialty & & & & \\
Family practice & 151 & $30(20)$ & $35(23)$ & $86(57)$ \\
Internal medicine & 67 & $12(18)$ & $21(31)$ & $34(51)$ \\
Emergency or urgent care & 32 & $4(13)$ & $15(47)$ & $13(41)$ \\
Pediatrics & 23 & $2(9)$ & $5(22)$ & $16(70)$ \\
Neurology & 19 & $6(32)$ & $2(11)$ & $11(58)$ \\
Rheumatology & 8 & $6(75)$ & $1(13)$ & $1(13)$ \\
Others & 56 & $12(21)$ & $16(29)$ & $28(50)$ \\
Total & 356 & $72(20)$ & $95(27)$ & $189(53)$ \\
Initiation of testing & & & & \\
Clinician initiated & 218 & $60(28)$ & $47(22)$ & $111(51)$ \\
Patient initiated & 95 & $8(8)$ & $37(39)$ & $50(53)$ \\
Not clear & 43 & $4(9)$ & $11(26)$ & $28(65)$ \\
Total & 356 & $72(20)$ & $95(27)$ & $189(53)$ \\
\hline
\end{tabular}

Table 3. Results of Univariate and Stepwise Multivariate Unconditional Logistic Regression Model Analysis for Factors Associated With Inappropriate Lyme Disease Serologic Testing

\begin{tabular}{|c|c|c|}
\hline Variable & $\begin{array}{l}\text { Univariate COR } \\
\qquad(95 \% \mathrm{Cl})\end{array}$ & $\begin{array}{l}\text { Multivariate AOR } \\
(95 \% \mathrm{Cl})\end{array}$ \\
\hline $\begin{array}{l}\text { Known or suspected tick bite within } 30 \text { days } \\
\text { of symptom onset }\end{array}$ & $6.9(2.9-16.5)$ & $6.8(2.6-17.6)$ \\
\hline $\begin{array}{l}\text { Test ordered by emergency or urgent care } \\
\text { physician }\end{array}$ & $3.7(1.2-11.4)$ & $5.2(1.3-20.6)$ \\
\hline Test initiated by patient request & $5.8(2.5-13.6)$ & \\
\hline Test done during summer & $2.5(1.3-4.7)$ & \\
\hline Patient age less than 40 years & $1.6(0.8-3.0)$ & \\
\hline $\begin{array}{l}\text { Initial evaluation of problem for which test } \\
\text { was ordered }\end{array}$ & $1.5(0.8-3.1)$ & \\
\hline Test done at Laboratory A & $1.1(0.4-2.9)$ & \\
\hline Test ordered by physician & $0.9(0.4-2.3)$ & \\
\hline Clinician in practice less than 10 years & $1.0(0.5-1.8)$ & \\
\hline Tick habitat exposure during last 30 days & $0.6(0.1-3.1)$ & \\
\hline Patient hospitalized & $0.3(0.1-1.0)$ & \\
\hline Patient referred from another clinician & $0.3(0.1-0.6)$ & \\
\hline
\end{tabular}

with family physicians and internists, physicians in emergency or urgent care were significantly more likely to order inappropriate tests. The reason for this finding is unclear, but we speculate that physicians in these settings may use testing as a temporizing measure, delaying final treatment decisions until the patient can follow up with his or her primary care physician. A known or suspected preceding tick bite was also strongly associated with inappropriate testing, suggesting a need for more clinician education on the risk of Lyme disease after a tick bite. A controlled study has shown that single-dose doxycycline given prophylactically can reduce the risk of Lyme disease after tick attachment in an endemic region, ${ }^{16}$ but there is no benefit to serologic testing regardless of the treatment decision. Interventions should be focused on educating providers about indications for Lyme disease testing, particularly that the absence of symptoms with or without a known or suspected recent tick bite obviates the need for testing.

We found $53 \%$ of all tests could not be classified as either appropriate or inappropriate based on published recommendations. The existing diagnostic guidelines base testing decisions on the pretest probability of Lyme disease as calculated by an expert panel. ${ }^{4}$ From a practical standpoint, clinicians and others might have difficulty calculating the pretest probability of Lyme disease; hence, the high proportion of discretionary tests.

We also found that patients requested a large number of tests, which is consistent with previous findings. ${ }^{6}$ Nearly $40 \%$ of these tests were inappropriate, although most inappropriate tests were initiated by physicians.

A limitation of this study is that clinical information was provided by clinicians without validation by medical record review, although respondents often used the medical record to complete the interview. In addition, 
sampling from 2 laboratories in Wisconsin might not be representative of all clinicians ordering LDSTs.

We conclude that inappropriate Lyme disease serologic testing is common in Wisconsin, and patients initiate many of these tests. Expanded education for clinicians and patients about testing indications and contraindications may reduce the number of inappropriate LDST requests. Clarification of existing testing guidelines is needed to promote optimal use of LDSTs.

To read or post commentaries in response to this article, see it online at http://www.annfammed.org/cgi/content/full/2/4/341.

Key Words: Lyme disease; serologic tests/utilization; Borrelia burgdorferi

Submitted July 28, 2003; submitted, revised, October 7, 2003; accepted October 17, 2003.

Presented in part at the 41st Interscience Conference on Antimicrobial Agents and Chemotherapy in Chicago, December 19, 2001.

Funding support: Centers for Disease Control and Prevention (Atlanta, GA) cooperative agreement on applied research in emerging infections - tick-borne diseases (\#UR8/CCU513366-01).

Acknowledgments: We are grateful to James Kazmierczak for his expert advice, Ned Hayes for his thoughtful review, Craig Gale and Lorelle Benetti for their technical assistance with the analysis, Deborah Hilgemann for her tireless interviewing efforts, and participating clinicians for their valuable time.

\section{References}

1. Burgdorfer W, Barbour AG, Hayes SF, Benach JL, Grunwaldt G, Davis JP. Lyme disease-a tick-borne spirochetosis? Science. 1982;216:1317-1319.

2. Steere AC, Grodzicki RL, Kornblatt AN, et al. The spirochetal etiology of Lyme disease. N Engl J Med. 1983;308:733-740.
3. Steere AC. Lyme Disease. N Engl J Med. 2001;345:115-125.

4. Tugwell $P$, Dennis DT, Weinstein A, et al. Laboratory evaluation in the diagnosis of Lyme disease. Ann Intern Med. 1997;127:1009-1023.

5. Steere AC, Taylor E, McHugh GL, Logigian EC. The overdiagnosis of Lyme disease. JAMA. 1993;269:1812-1816.

6. Ley $C$, Le C, Olshen E, Reingold AL. The use of serologic tests for Lyme disease in a prepaid health plan in California. JAMA. 1994;271:460-463.

7. Magri JM, Johnson MT, Herring TA, Greenblatt JF. Lyme disease knowledge, beliefs and practices of New Hampshire primary care physicians. J Am Board Fam Pract. 2002;15:277-284.

8. Bunikis J, Barbour AG. Laboratory testing for suspected Lyme disease. Med Clin North Am. 2002;86:311-340.

9. Seltzer EG, Shapiro ED. Misdiagnosis of Lyme disease: when not to order serologic tests. Pediatr Infect Dis J. 1996;15:762-763.

10. American College of Physicians. Guidelines for laboratory evaluation in the diagnosis of Lyme disease. Ann Intern Med. 1997;127:1106-1108.

11. Reid MC, Schoen RT, Evans JT, Rosenberg JC, Horwitz RI. The consequences of overdiagnosis and overtreatment of Lyme disease: an observational study. Ann Intern Med. 1998;128:354-362.

12. Sigal LH. The Lyme disease controversy: social and financial costs of misdiagnosis and mismanagement. Arch Intern Med. 1996;156:1493 1500.

13. Qureshi MZ, New D, Zulquami MJ, Machman S. Overdiagnosis and overtreatment of Lyme disease in children. Pediatr Infect Dis J. 2002;21:12-14.

14. Ettestad PJ, Campbell GL, Welbel SF, et al. Biliary complications in the treatment of unsubstantiated Lyme disease. J Infect Dis. $1995 ; 171: 360-361$

15. Centers for Disease Control and Prevention. Addressing Emerging Infectious Diseases: A Strategy For the 21st Century. Atlanta: U.S. Department of Human Services, Public Health Service; 1998.

16. Nadelman RB, Nowakowski J, Fish D, et al. Prophylaxis with singledose doxycycline for the prevention of Lyme disease after an Ixodes scapularis tick bite. N Engl J Med. 2001;345:79-84. 